\title{
Phase 4 Study in Patients From Asia With Gastroesophageal Reflux Disease Treated With Dexlansoprazole
}

\author{
Justin CY Wu, ${ }^{1 *}$ Bor-Shyang Sheu, ${ }^{2}$ Ming-Shiang Wu, ${ }^{3}$ Yong Chan Lee, ${ }^{4}$ and Myung-Gyu Choi ${ }^{5}$ \\ ${ }^{I}$ Department of Medicine and Therapeutics, Prince of Wales Hospital, Shatin, Hong Kong, China; ${ }^{2}$ Department of Internal Medicine, National \\ Cheng Kung University Hospital, Tainan City, Taiwan; ${ }^{3}$ Department of Internal Medicine, National Taiwan University Hospital, Taipei City, \\ Taiwan; ${ }^{4}$ Division of Gastroenterology, Department of Internal Medicine, Yonsei University Severance Hospital, Seoul, Korea; and ${ }^{5}$ Department \\ of Internal Medicine, The Catholic University of Korea, Seoul, Korea
}

\section{Background/Aims}

Since the use of dexlansoprazole in Asian subjects with gastroesophageal reflux disease (GERD) has not been adequately characterized, this study was conducted to evaluate the efficacy and safety of dexlansoprazole modified-release in Asian subjects with non-erosive reflux disease (NERD) and erosive esophagitis (EE).

\section{Methods}

In this phase 4, open-label, non-randomized, uncontrolled, multicenter, multi-country study sponsored by Takeda, subjects aged $\geq 20$ years with persistent typical GERD symptoms for at least 6 months underwent endoscopy. Based on endoscopic findings, they were assigned to either dexlansoprazole modified-release $30 \mathrm{mg}$ once-daily for 4 weeks (NERD group) or dexlansoprazole modified-release $60 \mathrm{mg}$ once-daily for 8 weeks (EE group). The primary endpoint was the percentage of days that subjects did not experience any 24hour heartburn or acid regurgitation.

\section{Results}

Of the 445 subjects screened from Hong Kong, South Korea, and Taiwan, 208 were enrolled in the NERD group (mean age: 53.6 years, male: $34.6 \%$ ) and 88 in the EE group (mean age: 51.7 years, male: $55.7 \%$ ). Over the treatment period, the median percentage of days that subjects did not experience any 24 -hour heartburn or acid regurgitation was $26.9 \%$ and $65.5 \%$ in the NERD and EE groups, respectively; for nighttime heartburn or acid regurgitation the proportions were $59.3 \%$ and $83.3 \%$, respectively. The treatment was well tolerated with low incidence of treatment-related adverse events in NERD and EE groups (6.7\% and $5.7 \%$, respectively).

\section{Conclusion}

In Asian patients with GERD, treatment with dexlansoprazole modified-release indicates a favorable efficacy and safety profile in relieving heartburn and acid regurgitation symptoms.

(J Neurogastroenterol Motil 2020;26:85-95)

\section{Key Words}

Asia; Dexlansoprazole; Esophagitis; Gastroesophageal reflux; Heartburn org/licenses/by-nc/4.0) which permits unrestricted non-commercial use, distribution, and reproduction in any medium, provided the original work is properly cited.

${ }^{*}$ Correspondence: Justin CY Wu, MD Department of Medicine and Therapeutics, Prince of Wales Hospital, 9/F, Lui Che Woo Clinical Science Building, Shatin, Hong Kong, China Tel: +852-3505-3174, Fax: +852-2637-3852, E-mail: justinwu@cuhk.edu.hk 


\section{Introduction}

Gastroesophageal reflux disease (GERD) is defined as a condition that develops when the reflux of stomach contents causes troublesome symptoms and/or complications. Non-erosive reflux disease (NERD) is defined by the presence of troublesome refluxassociated symptoms and the absence of mucosal breaks in the esophagus at endoscopy; when erosions are present, it is called erosive esophagitis (EE). ${ }^{1}$ GERD is a common condition. A recent meta-analysis reported a prevalence of 18.1-27.8\% in North America, 8.8-25.9\% in Europe, 2.5-7.8\% in East Asia, $8.7-33.1 \%$ in the Middle East, $11.6 \%$ in Australia, and $23.0 \%$ in South America. The prevalence of GERD appears to be increasing, especially in Asia, where the rates are beginning to approach those reported in Western countries. ${ }^{2-4}$

Patients generally consider mild symptoms occurring 2 or more days a week, or moderate/severe symptoms occurring more than 1 day a week to be troublesome. ${ }^{1}$ Frequent or severe GERD symptoms are associated with impaired quality of life and activities of daily living. ${ }^{5,6}$ These symptoms also result in decreased work productivity and increased costs. ${ }^{7}$ GERD is also commonly associated with nocturnal symptoms and sleep disturbances, which further contribute to disease burden. ${ }^{1,8,9}$

Proton pump inhibitors (PPIs) are the mainstay in the management of GERD.$^{10}$ However, a sizeable proportion of patients continue to experience persistent GERD symptoms despite treatment with the current PPIs. In a systematic review of the literature, the prevalence of persistent heartburn despite PPI treatment was 17\% in interventional non-randomized studies and $32 \%$ in randomized trials. ${ }^{11}$ The prevalence of persistent GERD symptoms despite treatment was $45 \%$ in observational studies. ${ }^{11}$ This persistence of symptoms results in increased burden, with patients reporting impaired sleep, impaired quality of life, reduced productivity, and increased cost of illness despite PPI treatment. ${ }^{10,12-14}$

Dexlansoprazole is a PPI that constitutes $>80 \%$ of circulating drug after oral administration of the PPI lansoprazole, and is more stable than lansoprazole. Dexlansoprazole modified-release is a novel modified-release formulation of dexlansoprazole, in which a dual delayed-release technology is used for extended duration of acid suppression. In this technology, 2 types of granules are used to ensure initial release of the drug in the proximal small intestine followed by a delayed release many hours later, in the distal small intestine. ${ }^{15}$ The safety and efficacy of dexlansoprazole has been demonstrated for the treatment of symptomatic GERD or NERD and safe and prolonged healing of $\mathrm{EE}$, and it is approved for use in many countries across the world. ${ }^{15,16}$

The registration studies for dexlansoprazole mostly involved doses of $60 \mathrm{mg} / \mathrm{day}$ and $90 \mathrm{mg} /$ day. In Asian subjects with GERD, the use of dexlansoprazole has not been adequately characterized at the dose regimens of $30 \mathrm{mg} /$ day for NERD and $60 \mathrm{mg} /$ day for EE. This phase 4 study was conducted to evaluate the efficacy and safety of the use of dexlansoprazole delayed-release in Asian subjects with GERD who manifest endoscopic evidence of NERD and EE.

\section{Materials and Methods}

This was a phase 4, open-label, non-randomized, uncontrolled, multicenter, multi-country study. Subjects were enrolled at 12 investigational sites in Asia, including 1 site in Hong Kong, 6 sites in South Korea, and 5 sites in Taiwan. Study sites mostly consisted of referral centers with expertise in GERD and with adequate facilities to perform study-related activities including endoscopy. The study was conducted from March 2015 to July 2016.

\section{Key Eligibility Criteria}

Male or female subjects aged $\geq 20$ years were eligible for the study if they had experienced persistent typical GERD symptoms (heartburn and/or acid regurgitation) for at least 6 months with the presence of GERD symptoms for at least 4 days within the past 7 days prior to the screening visit. Throughout the screening period the subjects documented the presence and maximum severity of daytime and nighttime heartburn and acid regurgitation symptoms each day in a paper diary. In addition, subjects were assessed for heartburn, acid regurgitation, dysphagia, belching, and epigastric pain as recorded by the investigator (clinician). During screening endoscopy, the subjects either needed to have macroscopically normal esophageal mucosa (NERD group) or have evidence of erosive esophageal reflux disease, Los Angeles (LA) classification grades B to $\mathrm{D}$ (EE group).

Key exclusion criteria related to the gastrointestinal system were as follows: known hypersensitivities to any PPI and component of dexlansoprazole; use of a histamine $\mathrm{H} 2$ blocker or a PPI other than dexlansoprazole during screening and throughout the study; previous use of dexlansoprazole before screening; endoscopic Barrett's esophagus and/or definite dysplastic changes in the esophagus; active gastric or duodenal ulcers within 4 weeks of the first dose of study drug; history of dilation of esophageal strictures other than a Schatzki's ring; coexisting disease affecting the esophagus, history 
of radiation therapy or cryotherapy to the esophagus, or caustic or physiochemical trauma; current or historical evidence of ZollingerEllison syndrome or other hypersecretory condition; history of gastric, duodenal, or esophageal surgery except simple oversew of an ulcer; and acute upper gastrointestinal hemorrhage within 4 weeks prior to endoscopy.

This study was registered with ClinicalTrials.gov (NCT 02351960; https://linicaltrials.gov/ct2/show/NCT02351960), and was conducted in accordance with the protocol, the ethical principles that have their origin in the Declaration of Helsinki, the $\mathrm{ICH}$ E6 GCP guidance, and all applicable regulations. Each subject (or the subject's legally authorized representative) signed and dated the informed consent form before undergoing any study participation. The study was reviewed and approved by the Institutional Review Boards/Independent Ethics Committees of all study sites, constituted according to the applicable local requirements of each participating region.

The names and numbers of the Institutional Review Boards are as follows:

- Institutional Review Board of Taichung Veterans General Hospital (SC15048A)

- Chang Gung Medical Foundation Institutional Review Board (104-0906A2)

- Institutional Review Board of The Catholic University of Korea (KC14MSGV0846)

- Asan Medical Center Institutional Review Board (20150014)

- Seoul National University Bundang Hospital Institutional Review Board (B-1412/277-008)

- Seoul National University College of Medicine/Seoul National University Hospital Institutional review board (H1411-076-626)

- Yonsei University Health System, Severance Hospital, Institutional Review Board (4-2014-1023)

- Samsung Medical Center Institutional Review Board (SMC-2014-11-079-001)

- Institutional Review Board, National Cheng Kung University Hospital (AB-CR-104-004)

- Joint CUHK-NTEC Clinical Research Ethics Committee (2014.681-T)

- Kaohsiung Medical University Chung-Ho Memorial Hospital Institutional Review Board (KMUHIRB$\mathrm{F}(\mathrm{I})-20150009$ )

- Research Ethics Committee, National Taiwan University Hospital (201412003MSB)

\section{Study Design}

Based on the results of the screening endoscopy, the subjects were assigned to either the NERD study group or the EE study group, and were treated as follows (these regimens were already approved in the countries where this study was conducted):

(1) NERD group: dexlansoprazole delayed-release $30 \mathrm{mg}$ once-daily (QD) for 4 weeks

(2) EE group: dexlansoprazole delayed-release $60 \mathrm{mg} \mathrm{QD}$ for 8 weeks

During the study, dexlansoprazole delayed-release was self-administered orally QD in the morning. Approximately 200 subjects were planned to be enrolled in the NERD study group and 100 subjects in the EE study groups. Subjects from Taiwan were to be enrolled in the EE group only because dexlansoprazole $30 \mathrm{mg}$ was not commercially available in the country.

\section{Outcomes}

During the study, efficacy was assessed via subject responses in a paper diary provided in local language (twice daily entries), investigator assessment of GERD symptoms (conducted at baseline and end of treatment, with an additional assessment at week 4 for subjects in the EE group), and via endoscopy (conducted at screening and, for subjects in the EE group, repeated at end of treatment).

The primary endpoints were as follows:

(1) The percentage of 24-hour heartburn and acid regurgitation-free days over 4 weeks in NERD subjects following study drug treatment, as assessed by subject entries in a daily paper diary (completed twice a day)

(2) The percentage of 24-hour heartburn and acid regurgitation-free days over 8 weeks in EE subjects following study drug treatment, as assessed by subject entries in a daily paper diary (completed twice a day)

Other efficacy endpoints included the assessment of the individual symptoms of heartburn and acid regurgitation separately, assessment for 24-hour and nighttime symptoms separately, investigator assessment of GERD symptoms, assessment of subject-rated severity of nighttime symptoms, and (in the EE group) the percentage of study subjects with endoscopically evaluated macroscopic healing of their esophagus, with at least $1 \mathrm{LA}$ grade classification grade improvement, at end of treatment.

\section{Paper diary}

Subjects documented the presence and maximum severity of daytime and nighttime heartburn and acid regurgitation symptoms 
each day in the paper diary, which was to be completed every morning upon waking and every evening before bedtime. The grading of the severity of heartburn and acid regurgitation by the subjects is shown in Table 1.

\section{Investigator assessment}

Clinicians (investigators) assessed the maximum severity of GERD symptoms (heartburn, acid regurgitation, dysphagia, belching, and epigastric pain) during the 7 days prior to the subject's

Table 1. Definitions of Heartburn and Acid Regurgitation Severity (Daytime/Nighttime) for Subject Daily Dairy

\begin{tabular}{|c|c|c|}
\hline $\begin{array}{l}\text { Severity (score } \\
\text { assigned) }\end{array}$ & $\begin{array}{l}\text { Definitions of daytime heartburn and acid regurgitation } \\
\text { severity (daytime = awake time) }\end{array}$ & $\begin{array}{l}\text { Definitions of nighttime heartburn and acid regurgitation } \\
\text { severity (nighttime = sleep time) }\end{array}$ \\
\hline None $(0)$ & No symptoms & No symptoms \\
\hline Mild (1) & $\begin{array}{l}\text { Occasional symptoms, can be ignored, does not influence daily } \\
\text { routine }\end{array}$ & Occasional symptoms, can be ignored, does not influence sleep \\
\hline Moderate (2) & $\begin{array}{l}\text { Symptoms cannot be ignored and/or occasionally influences } \\
\text { daily routine }\end{array}$ & $\begin{array}{l}\text { Symptoms cannot be ignored and/or occasionally influences } \\
\text { sleep }\end{array}$ \\
\hline Severe (3) & $\begin{array}{l}\text { Symptoms present most of day and/or regularly influences } \\
\text { daily routine }\end{array}$ & $\begin{array}{l}\text { Symptoms present most of night and/or regularly influences } \\
\text { sleep }\end{array}$ \\
\hline Very severe (4) & Constant symptoms and/or markedly influences daily routine & Constant symptoms and/or markedly influences sleep \\
\hline
\end{tabular}

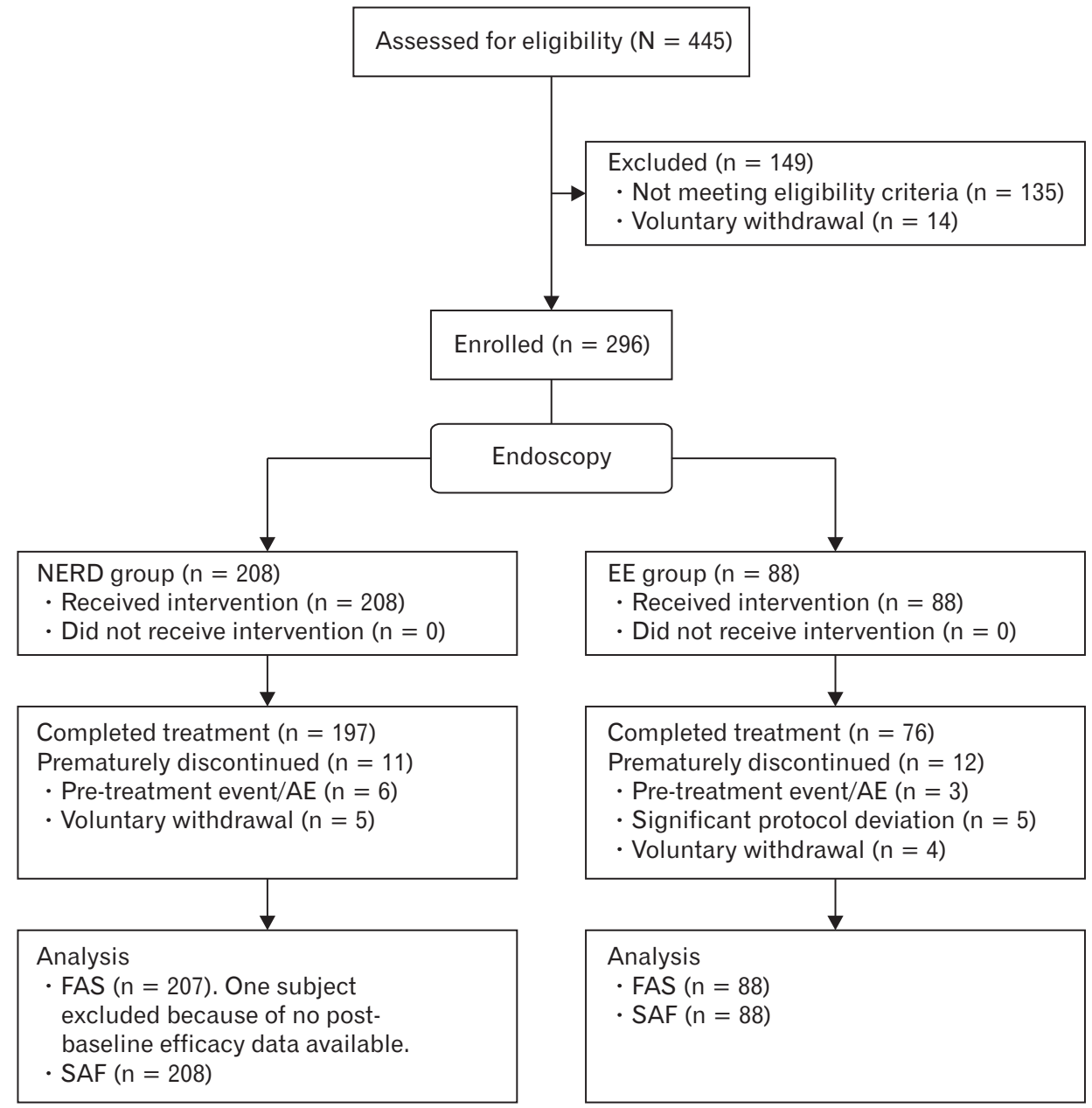

Figure 1. Flow diagram illustrating patients enrolled in the study. NERD, non-erosive reflux disease; EE, erosive esophagitis; AE, adverse event; FAS, full analysis set; SAF, safety analysis set. 
study visit. The severity of each symptom was rated from 0 (none, ie, no symptom) to 4 (very severe, ie, symptom caused intense and constant discomfort and/or marked interference with usual activities, including sleep).

\section{Statistical Methods}

No formal sample size calculation was performed for this study; a total of approximately 300 subjects were considered sufficient to achieve the study endpoints.

The percentage of 24-hour heartburn and acid regurgitationfree days were calculated for each subject with at least 1 daytime or nighttime heartburn and/or regurgitation result (yes or no) during treatment.

Summary statistics of percentage for the efficacy endpoints were generated for subjects in the full analysis set (all subjects who received at least 1 dose of study drug and had post-baseline data for

Table 2. Key Demographic and Baseline Characteristics, Including Baseline Subject-rated Heartburn and Acid Regurgitation Scores (Safety Analysis Set)

\begin{tabular}{|c|c|c|c|c|c|c|c|c|}
\hline Parameter & & \multicolumn{3}{|c|}{$\begin{array}{l}\text { NERD subjects; dexlansoprazole } \\
\qquad 30 \mathrm{mg}(\mathrm{n}=208)\end{array}$} & \multicolumn{4}{|c|}{$\begin{array}{l}\text { EE subjects; dexlansoprazole } \\
\qquad 60 \mathrm{mg}(\mathrm{n}=88)\end{array}$} \\
\hline Male gender (n [\%]) & & \multicolumn{3}{|c|}{$72(34.6)$} & \multicolumn{4}{|c|}{$49(55.7)$} \\
\hline Age (mean [SD], yr) & & \multicolumn{3}{|c|}{$53.6(13.6)$} & \multicolumn{4}{|c|}{$51.7(12.5)$} \\
\hline Body weight (mean $[\mathrm{SD}], \mathrm{kg}$ ) & & \multicolumn{3}{|c|}{$60.26(11.62)$} & \multicolumn{4}{|c|}{$68.84(14.99)$} \\
\hline $\mathrm{BMI}\left(\right.$ mean $\left.[\mathrm{SD}], \mathrm{kg} / \mathrm{m}^{2}\right)$ & & \multicolumn{3}{|c|}{$23.00(3.31)$} & \multicolumn{4}{|c|}{$25.11(4.16)$} \\
\hline \multicolumn{9}{|l|}{ 12-Lead ECG (n [\%]) } \\
\hline Within normal limits & \multicolumn{4}{|c|}{$141(67.8)$} & \multicolumn{4}{|c|}{$55(62.5)$} \\
\hline Abnormal but not clinically significant & \multicolumn{4}{|c|}{$67(32.2)$} & \multicolumn{4}{|c|}{$33(37.5)$} \\
\hline Abnormal and clinically significant & \multicolumn{4}{|c|}{$0(0.0)$} & \multicolumn{4}{|c|}{$0(0.0)$} \\
\hline \multirow[t]{2}{*}{$\mathrm{BMI}\left(\right.$ mean $\left.[\mathrm{SD}], \mathrm{kg} / \mathrm{m}^{2}\right)$} & \multicolumn{4}{|c|}{$23.00(3.31)$} & \multicolumn{4}{|c|}{$25.11(4.16)$} \\
\hline & $\mathrm{n}$ & Mean (SD) & $\begin{array}{l}\text { Me- } \\
\text { dian }\end{array}$ & Range & $\mathrm{n}$ & Mean (SD) & $\begin{array}{l}\text { Me- } \\
\text { dian }\end{array}$ & Range \\
\hline \multicolumn{9}{|c|}{ Number of days with heartburn or acid regurgitation (Days -8 to -2 ) } \\
\hline $\begin{array}{l}\text { Number of days with 24-hour heartburn or acid } \\
\text { regurgitation }\end{array}$ & 208 & $6.3(1.2)$ & 7.0 & $0-7$ & 88 & $6.0(1.6)$ & 7.0 & $0-7$ \\
\hline $\begin{array}{l}\text { Number of days with nighttime heartburn or } \\
\text { acid regurgitation }\end{array}$ & 208 & $5.0(2.3)$ & 6.0 & $0-7$ & 88 & $5.3(2.2)$ & 6.5 & $0-7$ \\
\hline $\begin{array}{l}\text { Number of days with daytime heartburn or } \\
\text { acid regurgitation }\end{array}$ & 208 & $5.6(1.8)$ & 6.0 & $0-7$ & 88 & $5.2(2.3)$ & 7.0 & $0-7$ \\
\hline \multicolumn{9}{|l|}{ Number of days with heartburn (Days -8 to -2 ) } \\
\hline Number of days with 24-hour heartburn & 208 & $5.6(1.9)$ & 7.0 & $0-7$ & 88 & $5.3(2.2)$ & 6.0 & $0-7$ \\
\hline Number of days with nighttime heartburn & 208 & $4.3(2.6)$ & 5.0 & $0-7$ & 88 & $4.5(2.6)$ & 5.5 & $0-7$ \\
\hline Number of days with daytime heartburn & 208 & $4.9(2.3)$ & 6.0 & $0-7$ & 88 & $4.5(2.6)$ & 5.0 & $0-7$ \\
\hline \multicolumn{9}{|l|}{ Number of days with acid regurgitation (Days -8 to -2 ) } \\
\hline Number of days with 24-hour acid regurgitation & 208 & $4.6(2.5)$ & 6.0 & $0-7$ & 88 & $4.8(2.6)$ & 6.0 & $0-7$ \\
\hline Number of days with nighttime acid regurgitation & 208 & $3.5(2.8)$ & 3.0 & $0-7$ & 88 & $4.3(2.8)$ & 4.0 & $0-7$ \\
\hline Number of days with daytime acid regurgitation & 208 & $3.9(2.7)$ & 4.0 & $0-7$ & 88 & $4.2(2.8)$ & 5.0 & $0-7$ \\
\hline \multicolumn{9}{|l|}{ Mean severity of heartburn ${ }^{a}$} \\
\hline Mean severity of 24-hour heartburn & 208 & $1.11(0.79)$ & 0.93 & $0.0-4.0$ & 88 & $1.12(0.87)$ & 0.93 & $0.0-3.8$ \\
\hline Mean severity of nighttime heartburn & 208 & $1.07(0.89)$ & 0.86 & $0.0-4.0$ & 88 & $1.13(0.96)$ & 1.00 & $0.0-4.0$ \\
\hline Mean severity of daytime heartburn & 208 & $1.16(0.81)$ & 1.00 & $0.0-4.0$ & 88 & $1.11(0.90)$ & 1.00 & $0.0-3.7$ \\
\hline \multicolumn{9}{|l|}{ Mean severity of acid regurgitation ${ }^{a}$} \\
\hline Mean severity of 24-hour acid regurgitation & 208 & $0.89(0.84)$ & 0.71 & $0.0-4.0$ & 88 & $1.10(0.96)$ & 0.89 & $0.0-3.8$ \\
\hline Mean severity of nighttime acid regurgitation & 208 & $0.86(0.90)$ & 0.57 & $0.0-4.0$ & 88 & $1.09(0.98)$ & 0.86 & $0.0-3.9$ \\
\hline Mean severity of daytime acid regurgitation & 208 & $0.93(0.87)$ & 0.71 & $0.0-4.0$ & 88 & $1.11(1.01)$ & 0.86 & $0.0-3.7$ \\
\hline
\end{tabular}

${ }^{\mathrm{S}}$ Scale for mean severity of heartburn and acid regurgitation: $1=$ mild, $2=$ moderate, $3=$ severe, $4=$ very severe.

BMI, body mass index; ECG, electrocardiogram; EE, erosive esophagitis; NERD, non-erosive reflux disease; SAF, safety analysis set. 
the appropriate efficacy variable) over 4 weeks in the NERD group and over 8 weeks in the EE group.

The safety analysis set included all subjects who received at least 1 dose of study drug. For subjects in the safety analysis set, the adverse event (AE) data and data on clinical laboratory tests, vital signs, physical examinations, and 12-lead electrocardiogram were summarized.

The Statistical Analysis System 9.2 or higher system for the UNIX operating system was used to perform the statistical analyses. Statistical review of the study was performed by a biomedical statistician.

\section{Results}

A total of 445 subjects were screened for the study: 208 subjects were enrolled into the NERD group and 88 subjects were enrolled into the EE group (Fig. 1).

\section{Demographic and Baseline Characteristics}

The key baseline and demographic characteristics, including baseline subject-rated heartburn and regurgitation scores are shown in Table 2.

The mean age of the subjects was 53.6 years in the NERD

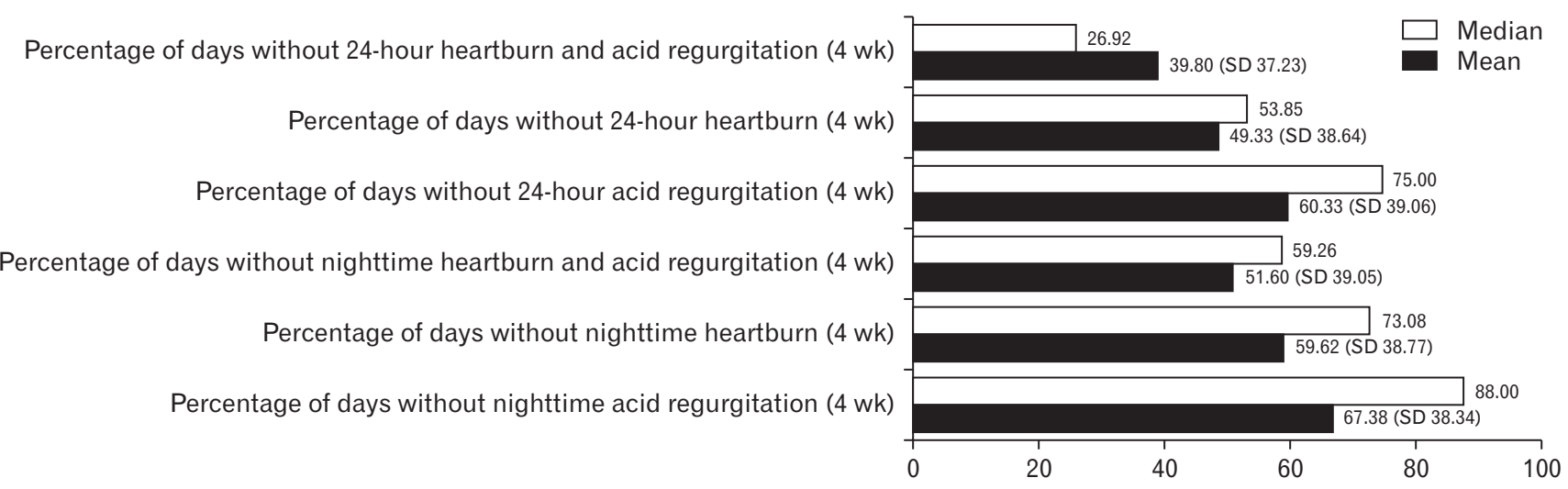

Figure 2. Percentage (\%) of days without heartburn and/or acid regurgitation in non-erosive reflux disease subjects; dexlansoprazole $30 \mathrm{mg}$ ( $\mathrm{n}=$ 207). For each parameter, the percentage of days ranged from 0 to 100.

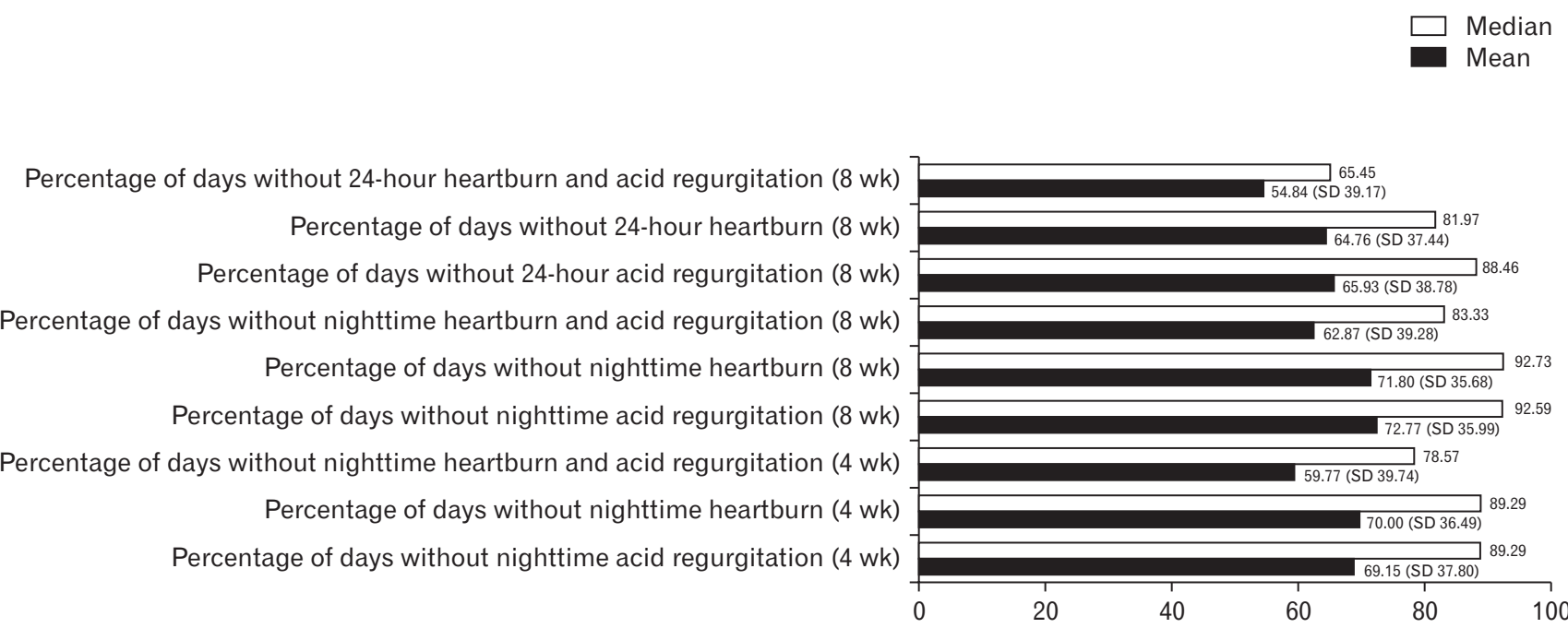

Figure 3. Percentage (\%) of days without heartburn and/or acid regurgitation in erosive esophagitis (EE) subjects; dexlansoprazole $60 \mathrm{mg}(\mathrm{n}=$ 88). One subject in the EE group only took 1 day of study drug and provided no valid diary. For each parameter, the percentage of days ranged from 0 to 100 . 
group and 51.7 years in the EE group. The mean body mass index was $23.00 \mathrm{~kg} / \mathrm{m}^{2}$ in the NERD group and $25.11 \mathrm{~kg} / \mathrm{m}^{2}$ in the EE group. In both the NERD and EE groups, for the 7 days prior to treatment with study drug, subjects experienced 24-hour heartburn or acid regurgitation for a median of 7 days. In both groups, daytime heartburn and acid regurgitation were more prevalent than nighttime heartburn and acid regurgitation.

\section{Efficacy Results}

The results of the subject-rated heartburn and acid regurgitation assessments following treatment with dexlansoprazole are shown in Figures 2 and 3 (Table 3). The median percentage of days that subjects did not experience any 24-hour heartburn and acid regurgitation was $26.92 \%$ in the NERD group and $65.45 \%$ in the EE group. The median percentage of days that subjects did not experience any nighttime heartburn and acid regurgitation was $59.26 \%$ in the NERD group and $83.33 \%$ in the EE group. For individual symptoms, the median percentage of days without nighttime heartburn was $73.08 \%$ and $92.73 \%$ respectively, and without nighttime acid regurgitation was $88.00 \%$ and $92.59 \%$ respectively, in the NERD and EE groups. The median severity (Table 3 ) of nighttime heartburn and of acid regurgitation ranged from 0.1 to 0.3 in the 2 groups.

Regarding investigator assessment, in the NERD group, the percentage of subjects who experienced an at least 1-category improvement in the severity of the symptom was $69.7 \%$ for acid regurgitation, $66.7 \%$ for heartburn severity, $64.3 \%$ for belching, $33.8 \%$ for epigastric pain, and $14.6 \%$ for dysphagia. Similarly, in the EE group, the percentage of subjects who experienced an at least 1-category improvement in the severity of the symptom was $71.0 \%$ for acid regurgitation, $63.2 \%$ for heartburn severity, $42.1 \%$ for epigastric pain, $40.8 \%$ for belching, and $17.1 \%$ for dysphagia.
The detailed endoscopy results are shown in Table 4. Of the subjects in the EE group, $77.3 \%$ experienced at least a $1 \mathrm{LA}$ grade improvement in EE from baseline to week 8, with 27 subjects (30.7\%) having no EE at week 8.

\section{Safety, Tolerability, and Compliance}

The median exposure to treatment was 27 days in the NERD group and 56 days in the EE group. In the NERD group, $96.2 \%$ of subjects showed $>90.0 \%$ drug compliance, while in the EE

Table 4. Number and Percentage of Subjects With Erosive Esophagitis With Endoscopically Evaluated Macroscopic Healing (Safety Analysis Set)

\begin{tabular}{lc}
\hline & \multicolumn{2}{c}{ Number of subjects (\%) } \\
\cline { 2 - 2 } Endoscopy evaluation & $\begin{array}{c}\text { EE subjects; dexlansoprazole } \\
60 \mathrm{mg}(\mathrm{n}=88)\end{array}$ \\
\hline Baseline (n [\%]) & $0(0.0)$ \\
No EE present & \\
Grade of EE & $1(1.1)$ \\
Grade A & $75(85.2)$ \\
Grade B & $10(11.4)$ \\
Grade C & $2(2.3)$ \\
Grade D & \\
Week 8 (n [\%]) & $27(30.7)$ \\
No EE present & \\
Grade of EE & $36(40.9)$ \\
Grade A & $12(13.6)$ \\
Grade B & $1(1.1)$ \\
Grade C & $0(0.0)$ \\
Grade D & $68(77.3)$ \\
At least 1 LA grade improvement & \\
from baseline (n [\%]) & \\
\hline EE, erosive esophagitis; LA, Los Angeles. &
\end{tabular}

Table 3. Subject-rated Nighttime Heartburn and Acid Regurgitation Severity Assessments in Subjects With Non-erosive Reflux Disease and Erosive Esophagitis (Safety Analysis Set)

\begin{tabular}{|c|c|c|c|c|c|c|c|c|c|c|}
\hline \multirow[b]{2}{*}{ Parameter } & \multicolumn{5}{|c|}{ NERD subjects; dexlansoprazole $30 \mathrm{mg}(\mathrm{n}=207)$} & \multicolumn{5}{|c|}{ EE subjects; dexlansoprazole $60 \mathrm{mg}(\mathrm{n}=88)$} \\
\hline & $\mathrm{n}$ & $\begin{array}{l}\text { Time- } \\
\text { point }\end{array}$ & Mean (SD) & $\begin{array}{l}\text { Me- } \\
\text { dian }\end{array}$ & Range & $\mathrm{n}$ & $\begin{array}{l}\text { Time- } \\
\text { point }\end{array}$ & Mean (SD) & $\begin{array}{l}\text { Me- } \\
\text { dian }\end{array}$ & Range \\
\hline \multicolumn{11}{|c|}{ Severity of nighttime heartburn and acid regurgitation ${ }^{a}$} \\
\hline Severity of nighttime heartburn & 207 & $4 \mathrm{wk}$ & $0.63(0.77)$ & 0.31 & $0.0-4.0$ & 87 & $8 \mathrm{wk}$ & $0.42(0.69)$ & 0.09 & $0.0-3.5$ \\
\hline Severity of nighttime acid regurgitation & 207 & $4 \mathrm{wk}$ & $0.49(0.71)$ & 0.15 & $0.0-4.0$ & 87 & $8 \mathrm{wk}$ & $0.38(0.58)$ & 0.09 & $0.0-2.7$ \\
\hline Severity of nighttime heartburn & - & - & - & - & - & 87 & $4 \mathrm{wk}$ & $0.46(0.73)$ & 0.11 & $0.0-4.0$ \\
\hline Severity of nighttime acid regurgitation & - & - & - & - & - & 87 & $4 \mathrm{wk}$ & $0.44(0.62)$ & 0.14 & $0.0-2.7$ \\
\hline
\end{tabular}

${ }^{a}$ Scale for mean severity of heartburn and acid regurgitation: $1=$ mild, $2=$ moderate, $3=$ severe, $4=$ very severe.

EE, erosive esophagitis; FAS, full analysis set; NERD, non-erosive reflux disease.

One subject in the EE group only took 1 day of study drug and provided no valid diary. 
Table 5. Frequency of Adverse Events in the Non-erosive Reflux Disease and Erosive Esophagitis Groups (Safety Analysis Set)

\begin{tabular}{|c|c|c|c|c|}
\hline \multirow{3}{*}{ Parameter } & \multicolumn{4}{|c|}{ Number of events or number of subjects (\%) } \\
\hline & \multicolumn{2}{|c|}{$\begin{array}{l}\text { NERD subjects; dexlansoprazole } \\
\qquad 30 \mathrm{mg}(\mathrm{n}=208)\end{array}$} & \multicolumn{2}{|c|}{$\begin{array}{l}\text { EE subjects; dexlansoprazole } \\
60 \mathrm{mg}(\mathrm{n}=88)\end{array}$} \\
\hline & Events & Subjects & Events & Subjects \\
\hline TEAEs & 53 & $35(16.8)$ & 59 & $31(35.2)$ \\
\hline Related & 22 & $14(6.7)$ & 5 & $5(5.7)$ \\
\hline Not related & 31 & $23(11.1)$ & 54 & $26(29.5)$ \\
\hline Mild & 36 & $26(12.5)$ & 41 & $29(33.0)$ \\
\hline Moderate & 13 & $11(5.3)$ & 15 & $7(8.0)$ \\
\hline Severe & 4 & $2(1.0)$ & 3 & $3(3.4)$ \\
\hline Leading to study drug discontinuation & 10 & $6(2.9)$ & 3 & $3(3.4)$ \\
\hline Serious TEAEs & 0 & $0(0.0)$ & 2 & $2(2.3)$ \\
\hline Related & 0 & $0(0.0)$ & 1 & $1(1.1)$ \\
\hline Not related & 0 & $0(0.0)$ & 1 & $1(1.1)$ \\
\hline Leading to study drug discontinuation & 0 & $0(0.0)$ & 1 & $1(1.1)$ \\
\hline Deaths & & $0(0.0)$ & & $1(1.1)$ \\
\hline
\end{tabular}

NERD, non-erosive reflux disease; EE, erosive esophagitis; TEAE, treatment-emergent adverse event.

group, $94.3 \%$ of subjects showed $>90.0 \%$ drug compliance.

Table 5 shows the frequency of AEs in the 2 groups. In the NERD group, $16.8 \%$ of subjects reported treatment-emergent AEs (TEAEs), with a small proportion of subjects (6.7\%) experiencing TEAEs related to the study drug. In the EE group, 35.2\% of subjects reported TEAEs, with $5.7 \%$ experiencing TEAEs related to the study drug. Most TEAEs were mild in intensity in both groups. No TEAEs were reported in $\geq 5.0 \%$ of subjects in either group. TEAEs that occurred in $2.0 \%$ or more subjects were headache in the NERD group (2.4\%) and diarrhea in the EE group (2.3\%).

TEAEs that led to study drug discontinuation were reported by 6 subjects in the NERD group and 3 subjects in the EE group. In the NERD group, there were no reports of serious AEs or deaths. In the EE group, 1 subject experienced a serious AE of mild urticaria on day 1, which was considered related to study drug; in addition, 1 subject experienced a treatment-emergent serious $\mathrm{AE}$ (SAE) leading to death. The death occurred in a 68-year-old male subject who experienced metastatic adenocarcinoma, diagnosed on omental nodule biopsy. The SAE start date was on day 66 (10 days after the last study treatment), and it lasted for 106 days. The patient also had comorbid hypertension, diabetes mellitus, and hyperlipidemia. The outcome of the metastatic adenocarcinoma was fatal and was considered not related to the study drug.

No clinically important findings were noted in the clinical laboratory, vital sign, or physical examination data.

\section{Discussion}

GERD is a common condition with an increasing prevalence in Asia. GERD symptoms can be troublesome and are associated with impaired daily living, poorer quality of life, decreased work productivity, and increased costs. A substantial proportion of patients continue to experience troublesome GERD symptoms despite treatment with the current PPIs. Dexlansoprazole delayed-release is a recently developed PPI with the novel dual delayed-release technology for extended duration of acid suppression. In Asian patients who require treatment for GERD, the effectiveness of the use of dexlansoprazole delayed-release has not been sufficiently characterized at the dose regimens of $30 \mathrm{mg} /$ day for NERD and $60 \mathrm{mg} / \mathrm{day}$ for EE.

In this large multicenter study conducted in 3 Asian countries, in subjects with NERD, dexlansoprazole delayed-release $30 \mathrm{mg}$ QD for 4 weeks relieved both daytime and nighttime heartburn and acid regurgitation. Symptom improvement was observed on both subject self-report and investigator ratings of GERD symptoms. For all the outcomes (except percentage of days without 24-hour heartburn and acid regurgitation), most patients reported relief for at least $50.0 \%$ of the days in the study. This finding should be understood in the context of the baseline status of the patients, during which the vast majority of the patients reported near-daily 24-hour heartburn or acid regurgitation symptoms (mean 6.3 days and median 7 days of heartburn or acid regurgitation in the 7 days prior to treatment). In subjects with $\mathrm{EE}$, whose baseline GERD symptom 
frequency was broadly comparable to that of subjects with NERD, dexlansoprazole delayed-release $60 \mathrm{mg}$ QD for 8 weeks relieved both daytime and nighttime heartburn and acid regurgitation on self- and investigator-ratings; most patients reported relief for at least $50.0 \%$ of the days on all outcomes. Three in 4 patients in this group experienced at least $1 \mathrm{LA}$ grade improvement in esophagitis, with approximately one-third of the patients showing no evidence of $\mathrm{EE}$ at the end of treatment. The mean severity of nighttime heartburn and nighttime regurgitation was also numerically lower at end of treatment than baseline status in both groups. An improvement in the frequency and severity of these symptoms can be expected to translate to better quality of life and productivity. ${ }^{17}$

The EE healing rate in this study (30.7\%) was lower than that seen in the dexlansoprazole pivotal trials in which the EE healing rate was higher than $80.0 \%$ after 8 weeks of treatment with dexlansoprazole. ${ }^{18}$ These pivotal trials were conducted mainly in North American and European centers. A review of studies with PPIs showed that EE healing rates were significantly lower in non-white patients than in white patients. ${ }^{19} \mathrm{~A}$ similar difference between Asian and non-Asian patients was reported in a pragmatic trial with pantoprazole for GERD ${ }^{20}$ Low EE healing rates were also reported in a Chinese study, in which $75.8 \%$ of patients experienced complete symptom resolution but only $48.0 \%$ showed complete healing of esophagitis after 8 weeks of treatment with esomeprazole $20 \mathrm{mg}$. ${ }^{21}$

Treatment with dexlansoprazole delayed-release $30 \mathrm{mg} /$ day in subjects with NERD for 4 weeks and $60 \mathrm{mg} /$ day in subjects with EE for 8 weeks was well tolerated. AEs related to the study drug were uncommon (6.7\% in the NERD group and $5.7 \%$ in the EE group), and AEs resulting in study drug discontinuation were reported in fewer than $4.0 \%$ of the subjects in each group. In the NERD group, over 4 weeks, no SAEs or deaths were reported. In the $\mathrm{EE}$ group, $1 \mathrm{SAE}$ leading to death was reported and it was not considered related to dexlansoprazole.

In subjects with $\mathrm{EE}$, the data suggested that further improvements in efficacy with treatment occurred during the period from 4 weeks to 8 weeks. As an example, the median severity of nighttime acid regurgitation was 0.14 at 4 weeks and 0.09 at 8 weeks. Similar numerical differences between week 4 and week 8 were seen for the other nighttime symptom parameters in subjects with $\mathrm{EE}$. It is possible that subjects with NERD may also have continued to show further improvement with a longer treatment period extending to 8 weeks or longer.

A comparison of outcomes between patients with NERD and EE shows that, at 4 weeks, the efficacy was consistently higher in EE patients than in NERD patients. While no statistical compari- sons were conducted, efficacy was numerically higher in EE for both daytime and nighttime symptoms, and for both heartburn and regurgitation symptoms; differences between EE and NERD were less pronounced for regurgitation symptoms. As an example, after 4 weeks of treatment, the mean percentage of days that subjects did not experience any nighttime heartburn was $70.0 \%$ in the EE group compared with $59.6 \%$ in the NERD group; for regurgitation symptoms, the respective percentages were $69.2 \%$ in the EE group and $67.4 \%$ in the NERD group. As noted earlier, GERD severity in both groups was broadly similar at baseline. While the dose of dexlansoprazole was lower in NERD patients than in EE patients, this is unlikely to explain the observed difference in outcomes; in NERD, the $30 \mathrm{mg}$ and $60 \mathrm{mg}$ doses of dexlansoprazole have showed comparable efficacy. ${ }^{15}$ This differential efficacy between EE and NERD appears to be related to the disease process itself, and is in keeping with the reported literature in which efficacy rates are consistently higher in EE than in NERD. ${ }^{22,23}$

The demonstration of improvement in both daytime and nighttime symptoms with a single daily dose of dexlansoprazole is encouraging. In a large recent survey (the GERD in Asia Pacific Survey), $45.0 \%$ of patients reported limited improvement in nocturnal symptoms despite regular treatment with PPIs. ${ }^{24}$ Therefore, dexlansoprazole, which has shown high response rates, 24-hour $\mathrm{pH}$ control, and reduction in nocturnal symptoms with once-daily dosing in this study, can be expected to meet an important medical need in Asian patients. ${ }^{25}$

A key limitation of this study was the absence of a comparator arm. No formal sample size calculation was performed for this study, and all patients received treatment with dexlansoprazole. Therefore, efficacy and safety of dexlansoprazole in comparison with placebo or an active comparator could not be established in this study. However, the overall efficacy and safety of dexlansoprazole delayed-release have been established in previous studies, and this treatment is already approved in Hong Kong, South Korea, and Taiwan. Therefore, an open-label uncontrolled study was sufficient to characterize the use of dexlansoprazole in the studied doses. Notably, the efficacy of dexlansoprazole was demonstrated not only on subjective assessments but also on endoscopic evaluations in subjects with EE. Another limitation of this study was that the statistical analyses were generally restricted to summary statistics; therefore, a detailed assessment of the factors associated with efficacy could not be conducted.

Future studies should focus on a longer duration of treatment with more frequent assessments to understand the trajectory of improvement with dexlansoprazole; studies should also attempt to 
identify those subgroups that are most likely to benefit with treatment with this drug.

In summary, in Asian patients with GERD, treatment with dexlansoprazole delayed-release $30 \mathrm{mg} /$ day for 4 weeks in subjects with NERD and $60 \mathrm{mg} /$ day for 8 weeks in subjects with EE indicated a favorable efficacy and safety profile in relieving both daytime and nighttime heartburn and acid regurgitation symptoms.

Financial support: Clinical trials were sponsored and conducted by Takeda Pharmaceuticals Company Ltd (Study No. DEXP4-001).

Conflicts of interest: Justin C Y Wu reports financial relationship with Takeda Pharmaceuticals and A. Menarini, outside the submitted work, while all the other authors report no conflict of interest. Medical writing support was provided by Assansa, India (a Healthcare Consultancy - Assansa consultants: Dr Aamir Shaikh, MD, and Dr Saifuddin Kharawala, MBBS, DPM) and sponsored by Takeda Pharmaceuticals Company Ltd.

Author contributions: Justin C Y Wu, Bor-Shyang Sheu, Ming-Shiang Wu, Yong-Chan Lee, and Myung-Gyu Choi made substantial contributions to the conception as well as study design along with data analysis and interpretation. Moreover, the authors contributed significantly in drafting the article as well as making critical revisions in the manuscript content. Lastly, all authors gave a final approval for this version of the article to be published.

\section{References}

1. Vakil N, van Zanten SV, Kahrilas P, Dent J, Jones R; Global Consensus Group. The Montreal definition and classification of gastroesophageal reflux disease: a global evidence-based consensus. Am J Gastroenterol 2006;101:1900-1920.

2. El-Serag HB, Sweet S, Winchester CC, Dent J. Update on the epidemiology of gastro-oesophageal reflux disease: a systematic review. Gut 2014;63:871-880.

3. Jung HK. Epidemiology of gastroesophageal reflux disease in Asia: a systematic review. J Neurogastroenterol Motil 2011;17:14-27.

4. Minatsuki C, Yamamichi N, Shimamoto T, et al. Background factors of reflux esophagitis and non-erosive reflux disease: a cross-sectional study of 10,837 subjects in Japan. PLoS One 2013;8:e69891.

5. Gisbert JP, Cooper A, Karagiannis D, et al. Impact of gastroesophageal reflux disease on patients' daily lives: a European observational study in the primary care setting. Health Qual Life Outcomes 2009;7:60.

6. Tack J, Becher A, Mulligan C, Johnson DA. Systematic review: the burden of disruptive gastro-oesophageal reflux disease on health-related quality of life. Aliment Pharmacol Ther 2012;35:1257-1266.

7. Bruley des Varannes S, Ducrotté P, et al. Gastroesophageal reflux disease: impact on work productivity and daily-life activities of daytime workers. A French cross-sectional study. Dig Liver Dis 2013;45:200-206.

8. Dubois RW, Aguilar D, Fass R, et al. Consequences of frequent nocturnal gastro-oesophageal reflux disease among employed adults: symptom severity, quality of life and work productivity. Aliment Pharmacol Ther 2007;25:487-500.

9. Wagner JS, DiBonaventura MD, Balu S, Buchner D. The burden of diurnal and nocturnal gastroesophageal reflux disease symptoms. Expert Rev Pharmacoecon Outcomes Res 2011;11:739-749.

10. Fock KM, Talley N, Goh KL, et al. Asia-Pacific consensus on the management of gastro-oesophageal reflux disease: an update focusing on refractory reflux disease and Barrett's oesophagus. Gut 2016;65:14021415.

11. El-Serag H, Becher A, Jones R. Systematic review: persistent reflux symptoms on proton pump inhibitor therapy in primary care and community studies. Aliment Pharmacol Ther 2010;32:720-737.

12. Gross M, Beckenbauer U, Burkowitz J, Walther H, Brueggenjuergen B. Impact of gastro-oesophageal reflux disease on work productivity despite therapy with proton pump inhibitors in Germany. Eur J Med Res 2010;15:124-130.

13. Bruley des Varannes S, Löfman HG, Karlsson M, et al. Cost and burden of gastroesophageal reflux disease among patients with persistent symptoms despite proton pump inhibitor therapy: an observational study in France. BMC Gastroenterol 2013;13:39.

14. Stålhammar NO, Spiegel BM, Granstedt Löfman H, et al. Partial response to proton pump inhibitor therapy for GERD: observational study of patient characteristics, burden of disease, and costs in the USA. Pragmat Obs Res 2012;3:57-67.

15. Fass R, Chey WD, Zakko SF, et al. Clinical trial: the effects of the proton pump inhibitor dexlansoprazole MR on daytime and nighttime heartburn in patients with non-erosive reflux disease. Aliment Pharmacol Ther 2009;29:1261-1272.

16. Sharma P, Shaheen NJ, Perez MC, et al. Clinical trials: healing of erosive oesophagitis with dexlansoprazole MR, a proton pump inhibitor with a novel dual delayed-release formulation--results from two randomized controlled studies. Aliment Pharmacol Ther 2009;29:731-741.

17. Wahlqvist P, Karlsson M, Johnson D, Carlsson J, Bolge SC, Wallander MA. Relationship between symptom load of gastro-oesophageal reflux disease and health-related quality of life, work productivity, resource utilization and concomitant diseases: survey of a US cohort. Aliment Pharmacol Ther 2008;27:960-970.

18. Fass R, Frazier R. The role of dexlansoprazole modified-release in the management of gastroesophageal reflux disease. Therap Adv Gastroenterol 2017;10:243-251.

19. Sharma P, Johnson DA, Monyak JT, Illueca M. Race affects healing of erosive oesophagitis in patients treated with proton pump inhibitors. Aliment Pharmacol Ther 2011;34:487-493.

20. Goh KL, Choi KD, Choi MG, et al. Factors influencing treatment outcome in patients with gastroesophageal reflux disease: outcome of a prospective pragmatic trial in Asian patients. BMC Gastroenterol 
2014;14:156.

21. Cheung TK, Wong WM, Wong NY, et al. Symptom resolution does not predict healing of erosive oesophagitis in Chinese. Digestion 2007;75:128-134.

22. Dean BB, Gano AD Jr, Knight K, Ofman JJ, Fass R. Effectiveness of proton pump inhibitors in nonerosive reflux disease. Clin Gastroenterol Hepatol 2004;2:656-664.

23. Orlando RC, Monyak JT, Silberg DG. Predictors of heartburn resolution and erosive esophagitis in patients with GERD. Curr Med Res
Opin 2009;25:2091-2102.

24. Goh KL, Choi MG, Hsu WP, et al. Unmet treatment needs of gastroesophageal reflux disease in Asia: gastroesophageal reflux disease in Asia Pacific survey. J Gastroenterol Hepatol 2014;29:1969-1975.

25. Goh KL, Choi MG, Hsu PI, et al. Pharmacological and safety profile of dexlansoprazole: a new proton pump inhibitor - implications for treatment of gastroesophageal reflux disease in the Asia Pacific region. J Neurogastroenterol Motil 2016;22:355-366. 